\title{
INTEGRATED NEAR-SURFACE GEOPHYSICS APPLIED TO CLAY PROSPECTION
}

\author{
Hugo Matias", João Carvalho ${ }^{* \nabla}$, L.Torres ${ }^{*}$ and Rui Gonçalves ${ }^{* *}$ \\ * Instituto Geológico e Mineiro \\ Estrada da Portela-Apartado 7586 \\ 2720 Alfragide - Portugal \\ jgameira@igm.pt, hmatias@igm.pt, torres@igm.pt \\ ${ }^{\nabla}$ Granted by JNICT \\ "Faculdade de Ciências da Universidade de Lisboa \\ Rua Escola Politécnica, 58 \\ 1200 Lisboa - Portugal \\ georuias@skull.cc.fc.ul.pt
}

\section{INTRODUCTION}

The area of study is of great importance for clay industry. Nevertheless, known clay reservoirs have become in the last years close to exhaustion. Also a clear delimitation of clay exploration areas, is essential from a land planning perspective, and is one of the major goals of the work of IGM in the area. In fact the area is being studied in a broader programme involving geological reconnaissance, geophysical surveys - mainly EM-34, selective mechanical drilling, clay sampling and technological tests on the materials.

Our goal here is to present results from a single line test were seismic and electrical data was collected and show the usefulness of such geophysical methods in this geological context. Over one single line 500 meters long, a seismic reflection line of more then 200 meters was acquired with the common-mid-point (CDP) geometry as well as Wenner profile, part of a more extensive survey, and three vertical electrical soundings (VES). For data control a well drilling of about 22 meters depth was performed on the seismic line.

The clay/sandstone interfaces are detected by seismic methods and show good correlation with geological stratigraphy and electrical methods. Results suggest that new clay reservoirs for exploration can be located to the North of the present area of extraction, provided the materials are of good quality.

\section{GEOLOGICAL SETTING}

The Alpedriz - Porto Carro synclinal produces a small oval shaped basin oriented approximately NE-SW. In the inside of the synclinal Cenozoic sediments overlay older deposits which present an average slope of $15^{\circ}-20^{\circ}$ to NW and NE. The stratigraphy of the region comprehends the following formations, from top to bottom:

Upper Jurassic - represented by clayey sandstones, often consolidated, intercalated with red, grey, purple and brown clays. These materials have been the purpose of intense exploration, judging by the number and dimension of clay quarries, most of them now deactivated ;

Lower Cretaceous - formed by sandy sediments occasionally conglomeratic, represented at the base by arkosis, yellow-brownish and reddish caulinitic sandstones. The upper part is characterised by fine grained sedimentation and interbeds of grey, brown, red and purple 
clays. This unit outcrops in the Juncal area of study and holds the clays that have been the purpose of intense exploration, being the main raw-material for ceramics in the region.;

Intermediate Cretaceous - the last formations are overlaid by marly limestones with an average thickness of 65 meters;

Tertiary formations - these units inconformatly overlay clayey sandstones with conglomerates and volcanic material at the base (Oligocene). Alluvium covers valleys and water lines;

Main faults affecting these formations are scarce and show 2 predominant directions: SW-NE and N-S.

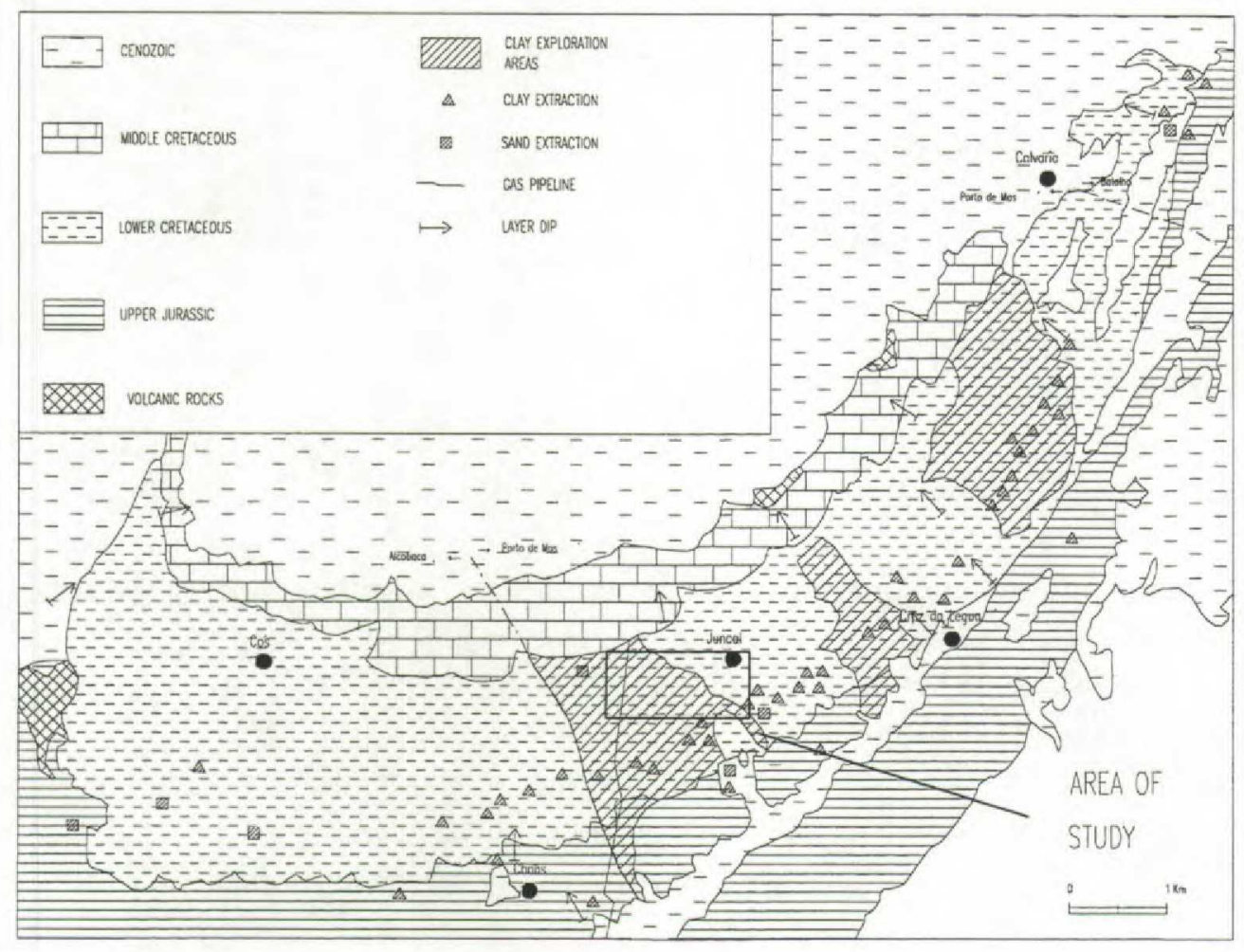

\section{DATA ACQUISITION}

The seismic reflection line was realised using the CDP geometry with a geofone spacing of 1 meter. A 24 channel EG\&G 2401 Geometrics seismograph was used, though 36 geofones and a roll-along-switch were used on the field. The source used was the hammer and steel plate and each shot consisted of ten stacked blows. A total of 109 shots were gathered at an interval of 2 meter providing 6 fold coverage. A digital sampling interval of 0.5 millisecond was used. A source to nearest geofone offset of 8 meter was chosen.

Standard seismic processing was applied to the data. Datum corrections, trace editing, first arrival muting and bandpass filtering were the first operations to be performed. After CDP sorting, velocity analysis were carried out along the profile. Direct stacking was then applied, after which residual statics and spiking deconvolution were executed and stacking velocities recalculated. Two-way-time to depth conversion was done using stacking velocities. The final section is presented here with AGC and variable area wiggle trace display.

The 500 meter long Wenner profile was obtained with an $A B=10 \mathrm{~m}$ and $\mathrm{MN}=2 \mathrm{~m}$, which gave us an approximate depth of investigation of 5 meter. Measurements were taken every 2 $\mathrm{m}$. The information was then plotted on a graph to allow determination of anomalous zones. Three vertical electrical soundings were done spaced 75 meters from each other and a 
maximum $\mathrm{AB} / 2$ of 100 meters, providing us information about the first 40 meters of the structure. The soundings were inverted and results of inversion are shown in the figure below.

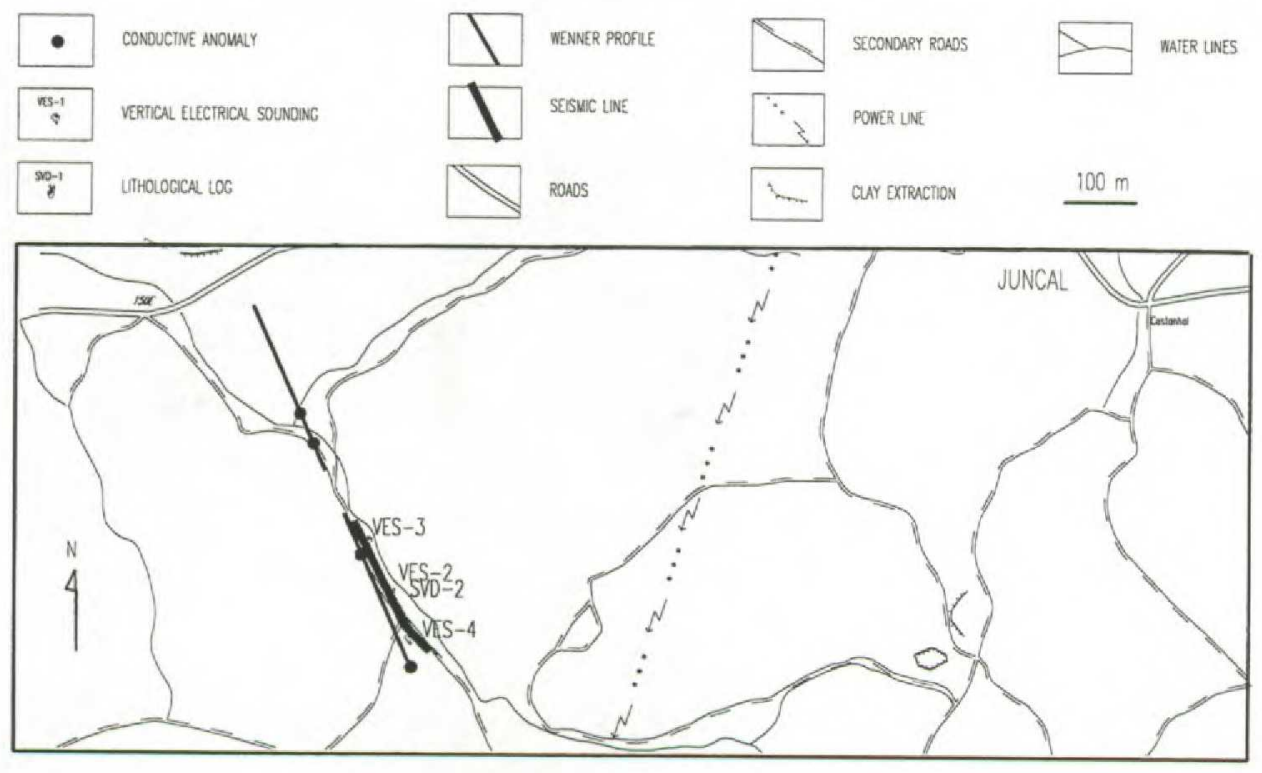

INTEGRATED INTERPRETATION

The interpretation resulting from the Wenner profile mapped several anomalous zones. This zones were detected considering values under the $500 \mathrm{Ohm} . \mathrm{m}$ boundary. Since geological information pointed that clay layers would have an approximate dip of 15 degrees it was decided to make the VES a few meters ahead the Wenner anomaly, this way we would still detect the clay layers if they were dipping.

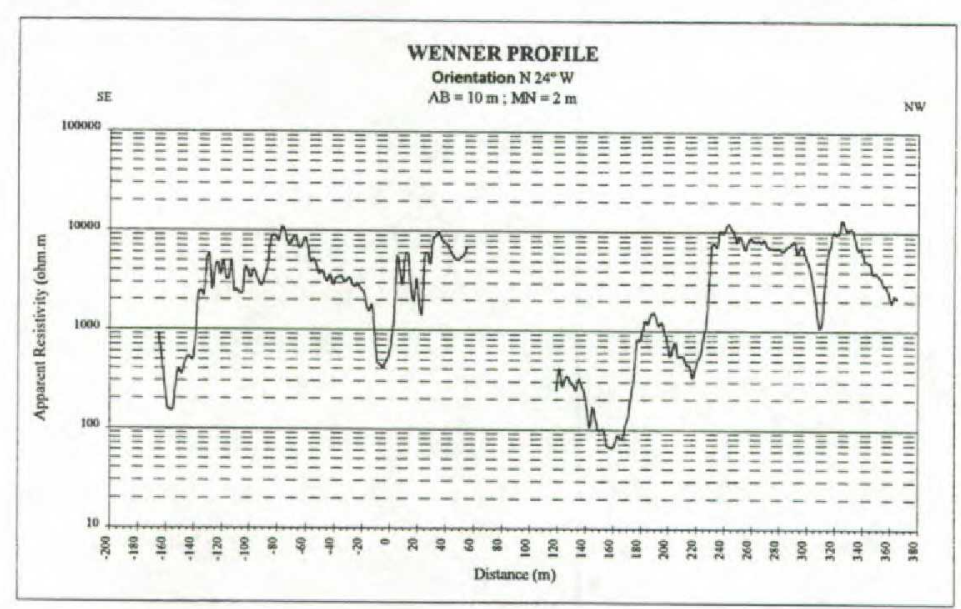

Four major reflectors can be identified to the right of station 30 on the seismic section, while to the left of that station only three events are seen. Other minor lens-shaped reflectors are also visible throughout the section. Below $120 \mathrm{~ms}$ ground-roll masks other possible reflectors. Above this value reflectors are undulating and laterally discontinuous. This patterns correlates well with the cross-stratification and sometimes laterally reduced lens-shaped clay beds which are expected for the formations in the area.

The lateral extension of the reflectors is limited not only by CDP spacing ( $1 \mathrm{~m}$ ) but also by the first Fresnel zone thickness. Considering that frequencies above $200 \mathrm{~Hz}$ are absent in the data, as shown by spectral analysis, and that the average speed of acoustic waves in those 
formations is about $550 \mathrm{~m} / \mathrm{s}$, we have a horizontal resolution of $1,5 \mathrm{~m}$ at two meter depth and of $5 \mathrm{~m}$ at 20 meter depth. Considering the same values of frequency and velocity we have that with less than $2 \mathrm{~m}$ are not detectable.
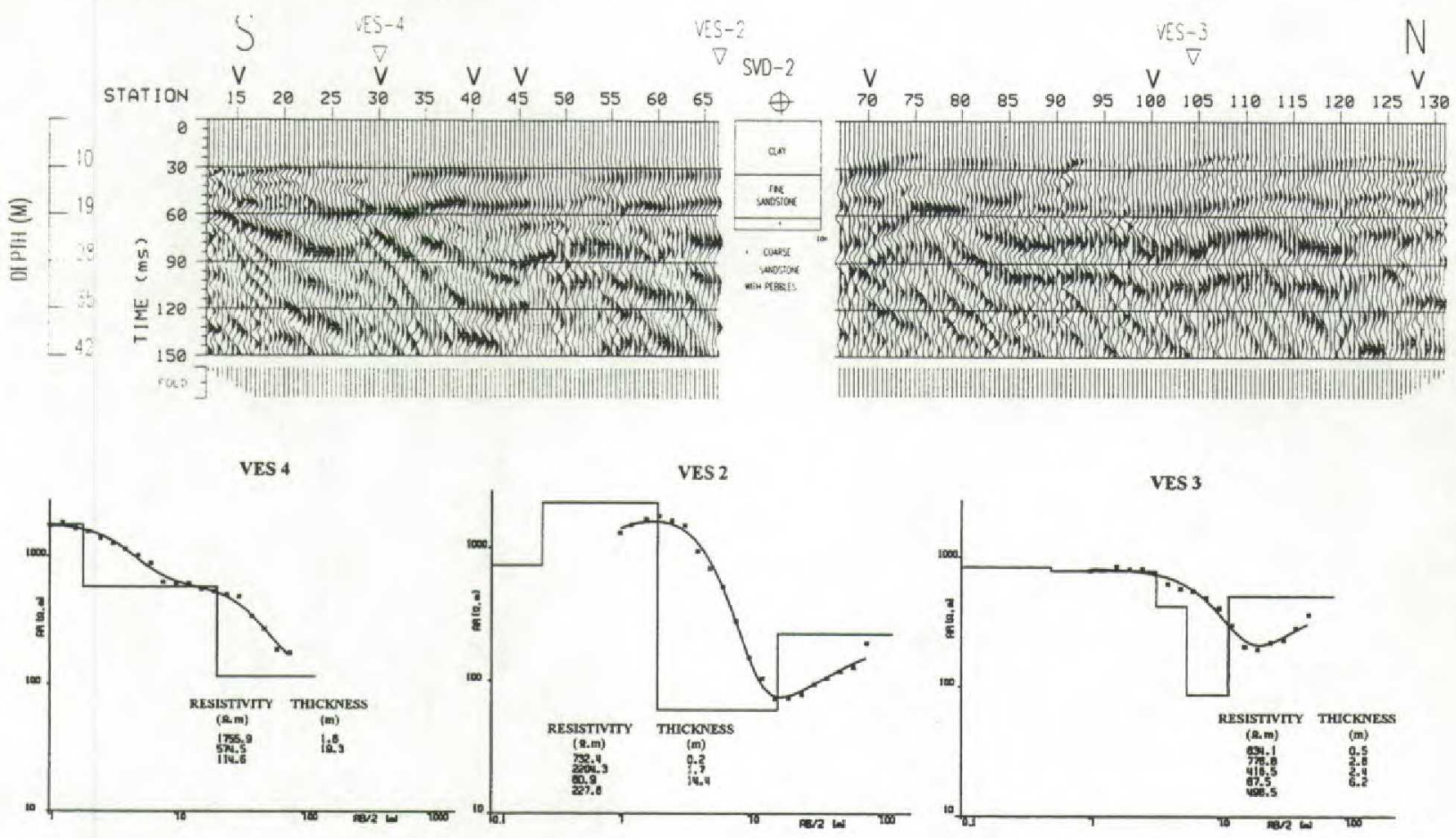

If we regroup formations neglecting beds with less than $2 \mathrm{~m}$ thickness, we have the following formations: i) clay bed with base located at about $11 \mathrm{~m}$ depth; ii) fine grained clayey sandstone whose base is at $20.56 \mathrm{~m}$; iii) coarse sandstone with pebbles; end of well at 21.86 $\mathrm{m}$. The first reflector on the seismic section matches perfectly with this interpretation while the second reflector is placed at $18.2 \mathrm{~m}$ depth. The $2 \mathrm{~m}$ difference in the second interface is probably due to error in the stacking velocities used in depth conversions.

So we can actually follow the bottom of the clay layer, which shows a good lateral continuity. It is nearly horizontal to the south of the well but moves upward to the north of it until station 75 , where the bottom is at a depth of $7 \mathrm{~m}$. The fading of the reflector is observed in some places, as over station 30 . These results are compatible with the interpretation of the vertical electrical soundings, which show similar depths for the interface and its almost disappearance over station 30 (VES 4). Results from inversion confirm this model. The values of resistivity for clays are around $60-90 \mathrm{Ohm} . \mathrm{m}$. As we can see, VES 2 shows a thick layer of clay with about 14 meters of thickness at a depth of $2 \mathrm{~m}$. This layer correlates with another layer found in VES 3 with a thickness of $6,2 \mathrm{~m}$ at a depth of 6 meters. This indicates that probably clay layers tend to dip with a lense like geometry.

\section{CONCLUSIONS}

It is shown here that seismic and electric results correlate well and can be helpful in the detection of clay/sandstone interfaces in the area. However due to inherent limitations to these methods, depths and thickness are not in total agreement. The seismic section was also important in providing an image which helps to constrain the geological model for the clay beds setting. Nevertheless, both methods allowed us to map a superficial clay bed of important lateral extension to the North of the present line of clay exploration. 